\title{
Extremely Rare Localization of Bladder Stone: Scrotal Bladder Hernia
}

\author{
(1) Mesut Berkan Duran1, (1) Yalçın Kızılkan², (1) Serdar Toksöz³, (1) Taha Numan Yıkılmaz4, (1) Hüseyin Dur5 \\ 1Samsun Training and Research Hospital, Clinic of Urology, Samsun, Turkiye \\ 2Ankara City Hospital, Clinic of Urology, Ankara, Turkiye \\ ${ }^{3}$ Hatay State Hospital, Clinic of Urology, Hatay, Turkiye \\ ${ }^{4}$ Kahramanmaraş City Hospital, Clinic of Urology, Kahramanmaraş, Turkiye \\ 5 Hatay State Hospital, Clinic of General Surgery, Hatay, Turkiye
}

\begin{abstract}
Inguinoscrotal bladder hernia is rarely encountered relative to the common occurrence of inguinal hernia. Most patients are asymptomatic and diagnosed perioperatively; however, lower urinary tract symptoms along with swelling in the inguinal region and two-stage urination may suggest herniated bladder. Co-occurrence of inguinoscrotal bladder hernia and herniated bladder stone is extremely rare, and there is no consensus on its treatment. Herein, we will present the case of an 81-year-old male patient with an inguinoscrotal bladder hernia and herniated bladder stone. To our knowledge, this is the seventh case reported in the literature thus far.
\end{abstract}

Keywords: Bladder stone, stone, scrotal hernia

\section{Introduction}

An inguinal hernia is common among all hernias (80-83\%); however, herniation of the bladder into the inguinal canal is a rare condition, which accounts for 1\%-3\% of hernia cases and occurs in 10\% of men aged $50-70$ years with obesity (1). Symptoms generally include inguinal pain or swelling associated with lower urinary tract symptoms (LUTS) and a decrease in scrotum size after voiding. Findings of ultrasonography (USG), computed tomography (CT) and cystography, as well as a physical examination, are used for diagnosis. Surgical repair is the best treatment option in large and symptomatic bladder hernias (1). Co-occurrence of an inguinoscrotal bladder hernia $(\mathrm{IBH})$ and herniated bladder stone is considerably rarer, and few cases have been reported in the literature (2-7). This paper aimed to present a patient who had IBH and herniated bladder stone and underwent surgery. To the best of our knowledge, this is the seventh case reported in the literature thus far.

\section{Case Presentation}

An 81-year-old male patient presented with swelling in the right groin for approximately 1 year, pollakiuria, difficulty in urination intermittently for 3 years and two-stage urination. He also had to squeeze his scrotum to complete urination. He had hypertension and had not undergone any surgeries. On physical examination, the patient had a large right inguinoscrotal hernia, and the swelling significantly decreased after micturition. Digital rectal examination revealed a large and smooth prostate. His body mass index was $31 \mathrm{~kg} / \mathrm{m}^{2}$, and his serum creatinine level and prostatespecific antigen were $0.9 \mathrm{mg} / \mathrm{dL}$ and $3.1 \mathrm{ng} / \mathrm{dL}$, respectively. The residual urine volume was $310 \mathrm{~mL}$, and the residual volume after voiding was $90 \mathrm{~mL}$ with a two-stage voiding pattern. Hernia sac and bladder herniation with stone were suspected on USG. CT showed that the bladder was herniated to the right scrotal region, and there was a $22 \mathrm{~mm}$ stone in the herniated part of the bladder (Figure 1). Cystoscopy was performed before right open inguinal hernioplasty and cystolithotomy under spinal anesthesia. The prostate was hypertrophic, the bladder mucosa was normal and no tumors or stones were detected in the bladder during cystoscopy. Thereafter, a right inguinal incision was performed, and the spermatic cord was found and retracted. The bladder was primarily repaired after the bladder was incised, and the stone was removed (Figure 1). The defect in the inguinal canal was repaired with polypropylene mesh, and the procedure was terminated after the herniated bladder

Correspondence: Mesut Berkan Duran MD, Samsun Training and Research Hospital, Clinic of Urology, Samsun, Turkiye

Phone: +90 5324817781 E-mail: drberkanduran@gmail.com ORCID-ID: orcid.org/0000-0002-8597-2081

Received: 01.07.2020

Accepted: 27.12 .2020

Cite this article as: Duran MB, Kızılkan Y, Toksöz S, Yıkılmaz TN, Dur H. Extremely Rare Localization of Bladder Stone: Scrotal Bladder Hernia. J Urol 2021;8(1):59-61.

${ }^{\circ}$ Copyright 2020 by the Association of Urological Surgery / Journal of Urological Surgery published by Galenos Publishing House. 


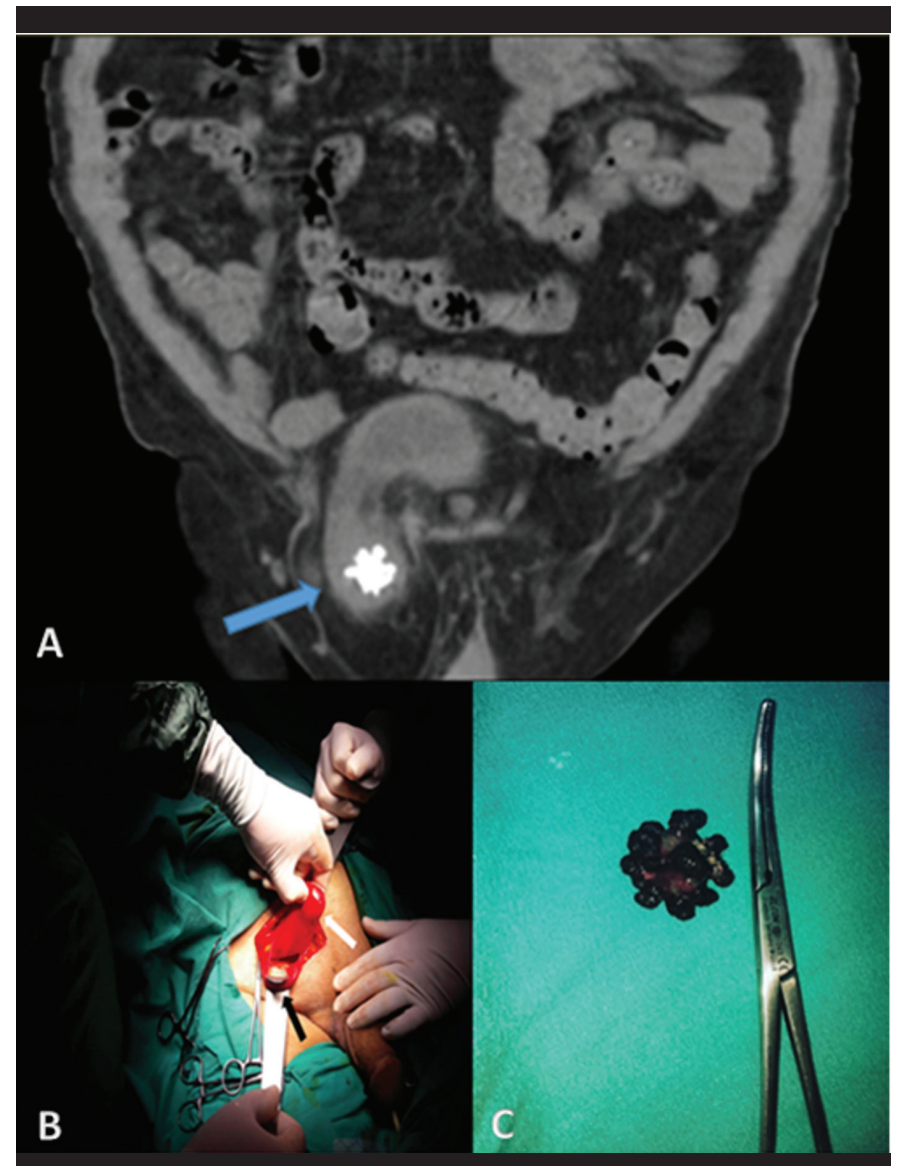

Figure 1. (A) Non-contrast CT coronal view demonstrates herniation of bladder into the right scrotum and view of the calculus inside the scrotum (blue arrow); (B) Spermatic cord (black arrow) and stone inside the herniated bladder (white arrow); (C) The stone removed from the herniated part of the bladder

CT: Computed tomography

was returned to its anatomical position. No problems were encountered in the postoperative follow-up, and the patient was discharged 3 days after the operation. The urinary catheter was removed on the seventh postoperative day. The two-stage voiding pattern disappeared at the six-week follow-up. Post voiding residual urine volume was $60 \mathrm{~mL}$. Written informed consent was obtained from the patient to report this case study and publication of images.

\section{Discussion}

Bladder herniation is usually observed on the right side (8). Older age, obesity, surgical history in the inguinal region, increased perivesical adipose tissue, and diseases that increase intravesical pressure such as benign prostatic hypertrophy (BPH) and neurogenic bladder are considered predisposing factors for herniation (9). In this case, similar to most reports, the hernia was on the right side, and age, obesity and clinical symptoms of $\mathrm{BPH}$ were considered predisposing factors.
While cystography is the golden standard diagnostic method, USG and CT can provide valuable information about the location and content of the hernia (8). As in this case, the preoperative diagnosis was made only in less than 7\% of IBH cases in patients undergoing inguinal hernia repair (8). CT should be performed prior to inguinal hernia repair in men aged $>50$ years with obesity, voiding symptoms and history of inguinal hernia repair. The standard treatment for IBH with bladder stone has not been established. Therefore, the patient's clinical conditions must be taken into consideration to determine the treatment method. Bladder resection can only be performed in cases with bladder wall necrosis, narrow hernia neck and tumors in the hernia bladder (10).

Postma and Smith (3) reported the first case of IBH with a herniated bladder stone. An 82-year-old male patient, who had LUTS and two-stage urination, was diagnosed with multiple calculi in the enlarged scrotum on direct radiography. Open hernia repair and open cystolithotomy were performed. Ptochos and losifidis (4) described a 67-year-old man who presented with acute retention of urine and opacity in the right groin, and this patient underwent open prostatectomy as well as open hernia repair and open cystolithotomy. In another study, a 77-year-old male patient who presented with acute urinary retention also had two-stage urination and open hernia repair and endoscopic cystolithotomy were performed (2). Moreover, a 55-year-old male patient presented with LUTS and swelling in the left hemiscrotum. His CT revealed two calculi in the herniated bladder, one of which was at the left ureterovesical junction. Open hernia repair, cystolithotomy in the region of the herniated bladder and extraction of the calculi from the bladder and ureter were performed (6). In a recent study, although an 82-year-old male patient was investigated for anemia, his CT showed a mass in the colon, right IBH and three stones with a diameter of 5-10 $\mathrm{mm}$ in the herniated bladder. The patient underwent open hernia repair, radical cancer surgery and endoscopic cystolithotomy (5). Two cases were reported in the latest study. The first case was not clinically different from previous cases. Unlike other cases, the 86-year-old patient was admitted with LUTS, hematuria and scrotal swelling. Dilatation was detected in the left renal pelvis and ureter on USG. CT showed that the herniating part of the bladder contained multiple calculi with a bladder tumor in the left wall. Open hernia repair, endoscopic cystolithotomy and bladder tumor resection were performed on this patient (7).

Although scrotal herniation of the stone-containing bladder is extremely rare, it should be considered in older men with LUTS who have an inguinal hernia. Urologists and general surgeons should be aware of the diagnosis and complications IBH. 


\section{Ethics}

Informed Consent: Written informed consent was obtained from the patient to report this case study and publication of images.

Peer-review: Internally peer-reviewed.

\section{Authorship Contributions}

Surgical and Medical Practices: S.T., H.D., Concept: Y.K., S.T., T.N.Y., Design: Y.K., S.T., T.N.Y., Data Collection or Processing: M.B.D., Analysis or Interpretation: M.B.D., Literature Search: M.B.D., Writing: M.B.D., Y.K.

Conflict of Interest: No conflict of interest was declared by the authors.

Financial Disclosure: The authors declared that this study received no financial support.

\section{References}

1. Curry N. Hernias of the urinary tract. Pollack HM, McClennan BL. Clinical urography. 3rd ed. Philadelphia, PA: Saunders, 2000: p. 2981-2991.
2. Ng AC, Leung AK, Robson WL. Urinary bladder calculi in a sliding vesicalinguinal-scrotal hernia diagnosed preoperatively by plain abdominal radiography. Adv Ther 2007;24:1016-1019.

3. Postma MP, Smith R. Scrotal cystocele with bladder calculi (case report). AJR Am J Roentgenol 1986;147:287-288.

4. Ptochos $A$, losifidis N. Lithiasic inguinoscrotal herniation of the bladder secondary to prostate enlargement. Acta Radiol 2002;43:543-544.

5. Inage $\mathrm{K}$, Mizusawa $\mathrm{H}$, Mimura $\mathrm{Y}$, Shimizu F. Patient with inguinal hernia containing the urinary bladder complicated by bladder stones. IJU Case Rep 2019;2:276-278.

6. Contrera JD, Cardoso Sobrinho FT. Sliding inguinoscrotal hernia insinuating itself into the bladder, with calculi in the bladder and distal ureter. Radiol Bras 2017;50:266-267.

7. Ahmed KB, Bouassida K, Ktari K, Jaidane M. Bladder hernia complicated with cystolithiasis and bladder tumor: Two cases' analysis. Urol Ann 2019;11:432-434.

8. Moufid K, Touiti D, Mohamed L. Inguinal bladder hernia: four case analyses. Rev Urol 2013;15:32-36.

9. Safavy S, Mitsinikos E, Tropea B, Chang A, Patel H. Obstructive Uropathy and Sepsis Caused by an Inguinoscrotal Bladder Hernia: A Case Report. Perm J 2018;22:17-052.

10. Gomella LG, Spires SM, Burton JM, Ram MD, Flanigan RC. The surgical implications of herniation of the urinary bladder. Arch Surg 1985;120:964967. 